\title{
IDENTIFICANDO CONCEPCIONES DE INFANCIA: UNA MIRADA A LOS
} PROYECTOS EDUCATIVOS INSTITUCIONALES

IDENTIFYING INFANCY CONCEPTIONS: AN INSTITUTIONAL EDUCATION PROJECT REVIEW

\section{Volumen 11, Número 2}

pp. 1-36

Este número se publicó el 30 de agosto de 2011

Nicole Cisternas Pacheco

Sandra Zepeda Aguirre

La revista está indexada en los directorios:

LATINDEX, REDALYC, IRESIE, CLASE, DIALNET, DOAJ, E-REVIST@S,

La revista está incluida en los sitios:

REDIE, RINACE, OEI, MAESTROTECA, PREAL, HUASCARAN, CLASCO 


\title{
IDENTIFICANDO CONCEPCIONES DE INFANCIA: UNA MIRADA A LOS PROYECTOS EDUCATIVOS INSTITUCIONALES
}

\author{
IDENTIFYING INFANCY CONCEPTIONS: AN INSTITUTIONAL EDUCATION PROJECT
} REVIEW

\author{
Nicole Cisternas Pacheco ${ }^{1}$ \\ Sandra Zepeda Aguirre ${ }^{2}$
}

Resumen: El presente artículo corresponde a una investigación cuyo foco alude a aquellas concepciones de infancia que construyen las escuelas. Para lo anterior, se utilizó como instrumento de análisis uno de sus dispositivos discursivos más relevantes: los Proyectos Educativos Institucionales (PEI). De esta manera, se seleccionaron 10 proyectos de escuelas de la Región Metropolitana de Chile insertas en contextos vulnerables. La metodología utilizada fue el Análisis de Discurso, a modo de identificar, a nivel textual e interpretativo, las diversas características y elementos que constituyen las nociones acerca de la infancia presentes en los discursos educativos. Las principales conclusiones que surgen de esta indagación son dos. La primera, en el plano textual vemos que la estructura de estos documentos imposibilita que aparezca la noción de infancia, que tiene como consecuencia la invisibilización del niño o la niña en el texto, pues al utilizar el formato de proyecto se privilegia la visión de futuro, los objetivos y las metas a lograr, en desmedro del proceso educativo presente. La segunda conclusión apunta al plano interpretativo, donde se aprecia que las concepciones de infancia presentes en los PEI revisados dan cuenta de tres características principales: la contradicción, porque conviven conceptos de la niñez basados en visiones contrapuestas, la invisibilización de niños y niñas en sus discursos al ser mencionados a través de categorías abstractas. Y la omisión del concepto de derechos de la infancia y carácter garante de la escuela.

Palabras clave: INFANCIA, VISIÓN TRADICIONAL, ENFOQUE DE DERECHOS, ANÁLISIS DE DISCURSO, PROYECTO EDUCATIVO INSTITUCIONAL.

\begin{abstract}
The next article response to an investigation that is focus on those infancy conceptions who are build by schools itself. For this investigation, an analysis instrument was used, as one of the most relevant discursive devices: the Educative Institutional Projects (PEI for its Spanish abbreviation) Hereby, 10 projects were chosen amongst schools insert in vulnerable contexts from the Region Metropolitana in Chile. The methodology used was the Analysis of Speech, in pursuit of identify in a textual and interpretative level the diverse characteristics and elements which constitute the infancy notions that lays in the educative speeches. The principal conclusions that they arise from this investigation come in two main lines. In textual plain we can see that the structure of these documents disables the appearance of the infancy notion, which brings as a consequence the invisibility of the children in the text because of the utilization of a project format which privileges a vision of future, the objectives and goals in spite of the main educative process. The second conclusion aims to an interpretative plain, where you can appreciate the conceptions of infancy laying onto the checked PEI delivering three principal characteristics: the contradiction because different concepts of childhood coexist based on opposed visions, the invisibility of children in their speeches for being mention throughout abstract categories, and the omission of the concept of children's rights and infancy rights and the school's role as a guarantor of it.
\end{abstract}

Key words: CHILDHOOD, TRADITIONAL VISION, RIGHTS APPROACHES, ANALYSIS OF SPEECH, INSTITUTIONAL EDUCATION PROJECT

\footnotetext{
${ }^{7}$ Trabajadora Social, Pontificia Universidad Católica de Chile, OMagister en Ciencias Sociales, mención Sociología de la Modernización, Universidad de Chile, Analista de Investigación y Desarrollo, Fundación Emmanuel, Chile. Dirección electrónica: nicole@fundacionemmanuel.cl

${ }^{2}$ Trabajadora Social, Pontificia Universidad Católica de Chile, Magister en Ciencias de la educación con mención en Evaluación, Pontificia Universidad Católica de Chile, (C) a Doctora en Estudios Americanos, mención Pensamiento y Cultura, Universidad de Santiago de Chile, Directora de Evaluación y Desarrollo Fundación Emmanuel, Chile. Dirección electrónica: sandra@fundacionemmanuel.cl
}

Artículo recibido: 31 de enero, 2011

Aprobado: 28 de julio, 2011 


\section{Introducción}

¿Cuándo aparecen los niños y niñas en la historia de las sociedades occidentales? ¿Existen diversas concepciones acerca de la niñez en la sociedad? Las respuestas a estas interrogantes se sustentan en la siguiente premisa: la infancia corresponde a una construcción social y cultural, que varía de una sociedad a otra y está estrechamente ligada a su cosmovisión y transformaciones de sus estructuras. "Es decir la infancia no fue considerada históricamente como una especificidad, con maneras particulares de sentir y pensar, sino que fue producto de una construcción social que la fue definiendo y delimitando hasta su objetivación" (Propper, 2001, p. 1).

Por lo tanto, la aparición del niño o niña, en tanto figura diferenciada en la estructura social, remite a la configuración de concepciones de infancia, es decir, cómo la sociedad a partir de sus diversas esferas e instituciones construyen un determinado concepto de lo que implica ser niño o niña

Las representaciones sociales corresponden al orden de lo imaginario, en cuanto son imágenes (no especulares) que condensan significados y se constituyen en sistemas de referencia que nos permiten interpretar y clasificar (...) son entendidas como juicios perceptuales que luego dan lugar de manera recursiva a categorizaciones y significaciones conceptuales del entorno social. (Ceirano, 2000)

De acuerdo con esto, la niñez y/o infancia no representa lo mismo, en todas las sociedades ni contextos, y siempre es co-definida de acuerdo a parámetros y cosmovisiones sociales.

Dentro de las esferas de la sociedad que han participado de la definición de concepciones de infancia aparece la escuela como institución clave, ocupando un rol protagónico en la construcción del concepto de niñez a lo largo de la historia, siendo la primera entidad en construir un discurso específico acerca de la niñez, modelándola a través de prácticas pedagógicas específicas

El concepto de infancia mantiene diferencias de acuerdo sea abordado por la psicología, historia, la antropología, la sociología, la pedagogía, e incluso la medicina. De todas estas, la pedagogía fue la única que produjo un discurso de la infancia, precisamente en el contexto escolar, ámbito donde se promueven los marcos disciplinares. (Satriano, 2008, p. 2) 
De acuerdo con lo anterior, la presente investigación tiene como foco de interés aquellas concepciones acerca de la infancia que levantan las escuelas; para lo cual se utilizó como instrumento de análisis uno de sus dispositivos discursivos más relevantes, a partir del cual se planifica y da forma a todos los procesos educativos: los Proyectos Educativos Institucionales

El Proyecto Educativo Institucional (en adelante PEI) es entonces el instrumento que orienta todos los procesos que ocurren en un establecimiento educacional, clarifica a los actores las metas de mejoramiento, da sentido y racionalidad a la gestión para el mediano o largo plazo, permite la toma de decisiones pedagógicas y curriculares, articula los proyectos y acciones innovadoras en torno al aprendizaje y la formación de los alumnos, en resumen, ordena las grandes tareas en torno a objetivos compartidos. (Villarroel, 2002, p. 5)

Al respecto, el propósito de esta investigación es: Analizar las concepciones de infancia que están presentes en los Proyectos educativos Institucionales de escuelas de contextos vulnerables de la Región Metropolitana de Chile, tanto de filiación religiosa católica como laica.

Para ello, se utilizó la técnica de Análisis de Discurso, tanto a nivel textual como interpretativo, a modo de rescatar las características, los conceptos y los elementos que constituyen las concepciones de infancia que emergen de los Proyectos Educativos de las escuelas.

\section{Marco teórico}

\subsection{Una mirada a la historia: Rastreando las concepciones de Niñez}

A lo largo de la historia han existido diversas nociones acerca de la infancia, ellas han sido iluminadas a partir de estudios, los que dependiendo de la disciplina de la cual provienen realizan acercamientos diferenciados al concepto.

De este modo, los énfasis han estado puestos en aspectos como: las representaciones sociales, los cambios en el ciclo vital, las transformaciones en los afectos y prácticas hacia la niñez, entre otros.

Uno de los trabajos pioneros y que marca la pauta para los estudios posteriores corresponde al trabajo de Philippe Ariés, este autor pone el foco en las representaciones sociales de la infancia, particularmente, busca determinar en qué momento surge la conciencia de la particularidad infantil, que distingue la infancia dentro del todo social. (Ariés 1960, en 
Rojas, 2001, p.2). Para ello, toma como referencia contextual la Europa del siglo XI hasta la del $\mathrm{XVIII}$, reconstruyendo el origen de la brecha que había distanciado a padres e hijos y delimitando un espacio propio y privativo para los niños, asignado un rol controlador a la familia y a la escuela. (Rojas, 2001, p.2).

Ariés en su estudio separa dos grandes periodos: la sociedad tradicional y la sociedad moderna. En la primera, la niñez se encuentra indiferenciada del todo social, la familia no cumplía un rol relevante en la socialización, ya que, por una parte, el aprendizaje de los niños se realizaba en la comunidad $y$, por otra, porque la función afectiva ocupaba un lugar secundario dentro de la familia dado que el amor no era indispensable que se desarrollara en su interior y los sentimientos hacia los niños eran superficiales. Se les veía como animalitos graciosos útiles para mimar, pero su presencia no era significativa. (Rojas, 2001)

En la sociedad moderna, producto de diversas transformaciones, se generan cambios en la vida íntima de las familias, las experiencias de socialización se trasladan del plano comunitario a la esfera familiar y posteriormente a la escuela; comienzan a transformarse los sentimientos y nociones acerca de la infancia. Aparece la ternura hacia los niños, sin embargo, existe un sentimiento ambivalente que contrapone dicha ternura con la severidad que supone la educación formal (Grupo de Trabajo Niñez, 2006).

A través de la escuela, el niño fue separado de la vida de los adultos y mantenido aparte, "en una especie de cuarentena, antes de dejarle suelto en el mundo". Esta reclusión lla escolarización), que Ariés equivale a la reclusión de los locos, los pobres y las prostitutas, iniciada en la misma época, se ha prolongado hasta el presente" (Rojas, 2001, p.7).

A partir del legado de Ariés e incluso en contraposición a su obra, aparecen estudios que integran otra mirada acerca de las concepciones de infancia. Autores como Shorter (1975), Badinter (1981), Stone (1990), y De Mause (1991), además de considerar el plano de las representaciones sociales, incluyen variables psicosociales, poniendo énfasis en "las prácticas" en relación con los niños, ya sea desde las relaciones filiales: formas y pautas de crianza (De Mause, 1991), como el trato y los sentimientos asociados (Rojas, 2001, pp. 7-10).

Si bien estos trabajos difieren en el énfasis con que se acercan al objeto de estudio, o en el periodo y contexto histórico que consideran, confluyen en la afirmación de que: los cambios en las esferas de la sociedad (económicos, políticos, culturales y demográficos) influyen en la manera de construir la infancia. Específicamente, pasamos de una época de indiferenciación de la niñez en el todo social hacia una identificación de los niños, expresada 
por una creciente valoración de su rol social, mayores niveles de control y más altas expectativas familiares que acentuaban su centralidad en la familia. (Rojas, 2001)

Vemos cómo la emergencia moderna de la infancia tiene como sustento el rol modelador de las instituciones; Estado y escuela aparecen como aliados en el proceso de configuración del sujeto niño: "No hay infancia si no es por la intervención práctica de un numeroso conjunto de instituciones modernas de resguardo, tutela y asistencia de la niñez (...) la niñez se nos aparece como un constructo moderno, fruto de un conjunto de prácticas promovidas desde el estado burgués que a su vez, lo sustentaron" (Satriano, 2008, p. 3).

\subsection{Repercusiones de las nociones de infancia en el ámbito educativo}

La infantilización, es decir, la conceptualización de la infancia en la sociedad, es inseparable de la formación de la pedagogía, pues muchas de las nociones que surgen en la sociedad acerca de los niños, así como también los sentimientos de amor, protección y las dinámicas relacionales establecidas con y hacia ellos, tienen como institución protagonista a la escuela, proceso que se ha denominado: Pedagogización de la infancia (Narodowski, 1994 en Propper, 2001, p. 3).

Dentro de este proceso de formación de la pedagogía moderna, la obra de Rousseau "El Emilio o de la educación" (Rousseau, 1966) ocupa un lugar fundamental. porque constituye el primer intento por caracterizar a la infancia desde una mirada pedagógica, concibiéndola como una etapa que antecede a la adultez, de tránsito, marcada por la inocencia, la dependencia, ausencia de juicio, pero sobre todo por la "carencia de razón".

Esta "condición natural" determina en gran medida el lugar de la educación, pues hace al niño educable, un ser con necesidad de aprender para ir transitando hacia la adultez. Pero, también, representa una suerte de desamparo, que justifica la autoridad adulta: "Rousseau planteaba que el adulto debe otorgar libertades al niño en función del respeto a la naturaleza infantil, pero esto es siempre una gracia, una concesión librada a favor de un correcto desarrollo humano" (Satriano, 2008, p. 2).

La educabilidad de la infancia supone un proceso de normativización, en el sentido de definir un modelo" normal" de niño, como aquel que debe aprender, pero es una situación pasiva, de sumisión, como "alumno". El docente es el portador de saberes que basa su mando y autoridad en una legitimidad, basada en sus conocimientos. "Los docentes son quienes 
determinan qué alumnos son buenos y cuáles malos. La pedagogía es el campo disciplinar que caracteriza a la infancia. La acción del niño será juzgada y corregida en relación con los instrumentos teóricos construidos para intervenir en ella" (Satriano, 2008, p. 5).

La alianza familia y escuela es la base del proceso de escolarización masiva, que tiene como antecedentes diversas transformaciones: sociales (cambios en la vida privada), demográficas (crecimiento poblacional, disminución de la mortalidad infantil), económicas (industrialización y especialización del mundo laboral), tecnológicas (desarrollo de las ciencias), por mencionar algunos, que potencian este ingreso masivo de los niños hacia las escuelas. "De esta manera, los padres aceptaron como legítima la cultura transmitida por la escuela, reconociendo que el pasaje por esa institución representaría la promesa de ascenso social para sus hijos" (Propper, 2001, p. 3).

La institución escolar, por lo tanto, construye todo un saber científico en torno a la niñez, implementando un currículum donde el lugar central está ocupado por el adulto, quien entrega saber y disciplina, relegando al niño a un lugar secundario, en una posición asimétrica, de dependencia y obediencia.

En síntesis, vemos como la modernidad representa este movimiento de separación y distinción de la niñez y la adultez, donde se va construyendo un imaginario acerca de los niños, conocido como la visión tradicional de la infancia, el cual destaca su "condición" de dependencia, considerándolos como seres inacabados, incompletos, carentes de razón, frágiles, con necesidades de protección de parte del mundo adulto

Es en función de este tipo de consideraciones como se fija la longitud del período de la infancia, la distribución del tiempo de los niños o las restricciones a su participación en la vida social. Las pautas, normas y regulaciones que dictan las actitudes hacia aquellos definidos como niños, son únicas y particulares para cada sociedad (Gaitán, 2006, p. 67).

\subsection{Cambios en la noción tradicional de infancia: el enfoque de derechos}

La concepción tradicional de infancia perdura gran parte del siglo XX e incluso aún convive con visiones más contemporáneas como la que consagra la Convención Internacional sobre los Derechos del Niño (a), aprobada en 1989.

Este instrumento reconoce expresamente a las niñas y los niños como sujetos de derechos, para lo cual establece la necesidad de crear un sistema de protección especial e 
integral. "La diferencia más importante de la Convención, con respecto a las anteriores Declaraciones, es la consideración de los menores de edad como "sujetos de derechos", antes que como meros «objetos» de protección” (Gaitán, 2006, p. 66).

Este enfoque de derechos se considera como una respuesta al enfoque más tutelar o proteccionista respecto de la infancia, que prevalecía hasta el momento en las políticas públicas y en las formas de intervención de las distintas instituciones que trabajan con niñas y niños, tanto en Chile como en el mundo. El enfoque tutelar está anclado en la concepción tradicional de infancia, por ende, ve al niño como un receptor de beneficios, desconociendo su condición de sujeto de derechos.

El concepto de infancia, como sujeto de derechos, es fruto del debate y propuestas generadas por distintos movimientos reformistas, tanto del ámbito de las ciencias sociales, educación, como del plano jurídico, quienes nuevamente insertan en lo público la preocupación por la infancia, a nivel discursivo y de prácticas institucionales.

Este enfoque de derechos transforma las visiones tradicionales de infancia, pues parte del supuesto de que niños y niñas, en tanto tales, constituyen actores sociales. "Una concepción de infancia que parta del reconocimiento de los derechos de la niñez, conlleva la necesaria transformación de una visión de los niños y niñas como objetos sociales hacia una que los reconozca como sujetos" (Quinteros, 2003, p. 61).

En este sentido, el enfoque de derechos puede concebirse como un nuevo modo de definir la relación del Estado con la infancia, pues la Convención es el primer instrumento internacional jurídicamente vinculante que incorpora toda la gama de derechos humanos: civiles, culturales, económicos, políticos y sociales. Su carácter vinculante implica que la Convención adquiere rango constitucional en los países que adscriben a ella, los gobiernos asumen su papel de principal responsable de proteger y asegurar tales derechos (Zepeda, 2008).

Los derechos que este instrumento establece pueden ser clasificados en tres tipos: Provisión, Protección y Participación. La provisión se refiere al derecho a poseer, recibir o tener acceso a ciertos recursos y servicios, a la distribución de los recursos entre la población infantil y adulta. La protección consiste en el derecho a recibir cuidado parental y profesional, y a ser preservado actos y prácticas abusivas, la participación expresa el derecho a hacer cosas, expresarse por sí mismo y tener voz, individual y colectivamente. (Gaitán, 2006). Además, se 
basa en 4 principios: igualdad y no discriminación, interés superior del niño/a, efectividad y prioridad absoluta y principio de solidaridad.

En el caso de Chile, la Convención fue ratificada en 1990 y marcó consolidación de las políticas de infancia

madurando la noción de que el niño ya no debía ser un objeto de protección, sino un sujeto portador de derecho (...) La idea de defender el "interés superior del niño" se hizo recurrente en el discurso gubernamental. Pero sus alcances superarían el estricto campo del derecho. A diferencia de otras épocas, el concepto de derechos del niño penetró por diversas vías en la población y se instaló en la vida cotidiana. (Rojas, 2010, p. 782)

\subsection{Cohabitación de 2 visiones de infancia}

Pese a todas estas transformaciones, respecto de la manera de concebir la infancia como sujetos de derechos, a nivel social, cultural, y sobretodo institucional, existe una suerte de hibridación respecto de las concepciones de infancia, pues permanecen instalados discursos y prácticas correspondientes tanto a nociones tradicionales, como también aquellas asociadas al enfoque de derechos.

Esta coexistencia de visiones, resulta paradójica, puesto que ambas se construyen (al menos en el plano formal) en contraposición, y de hecho el enfoque de derechos nace como una crítica explícita a los discursos y a las prácticas basadas en este marco tradicional. Dentro de las diferencias de ambos enfoques es posible destacar dos ámbitos que influyen enormemente en las prácticas educativas: el rol del Estado y el concepto de niñez (Zepeda, 2008).

No obstante, y a esta aparente superioridad del enfoque de derechos, existen diversas críticas a este último, pues pareciese ocurrir una nueva contradicción al interior de la noción de niños como sujeto de derechos, expresada en una cohabitación de dimensiones asociadas al concepto tradicional de infancia (énfasis en los derechos de protección en desmedro de los de participación), como de otras enfocadas en la autonomía de los niños. "La visión de los niños como seres dependientes y de la infancia como etapa de preparación queda reflejada $y$ reforzada en la Convención. Esto conduce a contradicciones que desafían los principales impulsos innovadores que la misma propone" (Rojas, 2001, p.26). 


\section{Objetivos y Metodología de la investigación}

\subsection{Objetivo general}

Analizar las concepciones de infancia que están presentes en los Proyectos educativos Institucionales de escuelas de contextos vulnerables de la Región Metropolitana, tanto de filiación religiosa católica como laica.

\subsection{Objetivos específicos:}

- Analizar las características de los Proyectos Educativos Institucionales, a partir de criterios situacionales, funcionales $y$ textuales.

- Identificar los conceptos y características de las concepciones de infancia presentes en los Proyectos educativos Institucionales.

\subsection{Metodología}

El presente estudio utilizó la perspectiva cualitativa como enfoque metodológico, esta decisión se fundamenta dado que el objetivo es analizar las concepciones de infancia presentes en los discursos formales de las escuelas, en este caso los PEI. Al respecto del enfoque: "Una descripción cualitativa quiere captar la estructura interna del objeto, su propia red de determinaciones, su singularidad... es un saber que se constituye en la propia experiencia del investigador que se expone al objeto y a sus formas" (Canales, 1994).

En este sentido, conocer desde una perspectiva cualitativa implica considerar los fenómenos sociales a partir de los significados que los propios sujetos construyen, observar cómo estos le observan, y lo nombran a través de sus discursos.

Se ha utilizado como técnica el análisis de discurso, ya que se considera que tanto el discurso hablado como el escrito son formas de la práctica social en un contexto sociocultural, esta premisa supone asumir una relación dialéctica entre un suceso discursivo particular y las situaciones, instituciones y estructuras sociales que lo enmarcan (Van Dijk, 2001).

Este análisis se realizó a partir dos componentes:

1. Nivel textual: caracterización del corpus como objeto de estudio y definición de la macro estructura textual.

2. Nivel interpretativo: análisis del corpus con base en tópicos relativos a las concepciones de infancia que se extraen del marco teórico. 
Respecto del corpus, este se compone de 10 PEl elaborados posterior a la ratificación en Chile de la Convención de los Derechos de los niños y niñas ${ }^{3}$, pertenecientes a escuelas de contextos vulnerables ${ }^{4}$ de la Región Metropolitana en Chile, tanto de filiación religiosa como laicos. Específicamente los proyectos revisados corresponden a las siguientes instituciones:

- Centro educacional Menesiano de Culiprán, comuna de Melipilla.

- Colegio San Alberto Hurtado, comuna de Quilicura.

- Colegio Los Nogales, comuna de Puente Alto.

- Sociedad de Instrucción Primaria red de colegios, Santiago.

- Colegio Quitalmahue, comuna de Puente Alto.

- Liceo Alto Jahuel, comuna de Buin.

- Colegio Nazaret, comuna de la Florida.

- Colegio El Cristo de Chiñigue, comuna El Monte.

- Colegio Villa Independencia, comuna de Puente Alto.

- Colegio Santa Luisa de Marillac, comuna de Huechuraba.

\section{Resultados de la investigación}

Los resultados de la investigación se presentan en dos niveles de análisis: textual e interpretativo.

\subsection{Análisis textual}

Para el análisis del corpus se utilizó el enfoque multiniveles (Gramajo y Parodi, 2003) por cuanto permite una aproximación más integral a los textos, incluyendo en el análisis tanto las características textuales como del contexto de producción.

El enfoque multiniveles incluyó 3 criterios de análisis con los siguientes hallazgos (Gramajo y Parodi, 2003): Nivel Situacional, Nivel Funcional y Nivel Textual explicados a continuación.

Este criterio es clave para distinguir entre visiones tradicionales y más contemporáneas de la infancia.

Consideramos a escuelas insertas en este tipo de contextos dada nuestra misión institucional de trabajar para mejorar la calidad de la educación de personas que viven en situación de pobreza, vulnerabilidad o exclusión. 
4.1.1 Nivel Situacional/5: caracterización del contexto donde el texto es producido, que se describe a través de los siguientes rasgos:

- Ámbito de producción original: corresponde al contexto específico donde se produjeron estos PEl. La mayor parte del corpus fue elaborado en el espacio escolar, es decir, forman parte de un proceso de reflexión y construcción discursiva que ocurre al interior de la comunidad educativa. Sin embargo, en el caso de proyectos de establecimientos de filiación religiosa éstos se encuentran enmarcados en Proyectos Congregacionales de las Comunidades religiosas de las que forman parte.

- Audiencia original: alude a la relación entre escritor y lector que plantea el texto, específicamente al tipo de audiencia a la que se dirige en términos de su nivel de conocimiento del tema. Este corpus se orienta mayoritariamente a una audiencia experta o semi-lega, pues el estilo de los escritos es bastante formal e incluye conceptos técnicos asociados al ámbito educativo y organizacional. Además, está dirigido a una audiencia externa al colegio, especialmente la sociedad, no se dirigen a la comunidad educativa, pues adjetivos posesivos como el nuestro, nosotros, nos, no son conceptos muy presentes en el corpus.

- Autoría: refiere al autor del texto, examina si está implícito o explícito; y si se trata de un texto escrito en conjunto con la comunidad educativa (profesores, directivos, estudiantes y familias) o ha sido producido solo por alguno de estos actores. Respecto de este criterio, el corpus oscila desde aquellos PEI donde la autoría es explícita, mencionándose que es un documento producido mediante un proceso comunitario y participativo, hasta aquellos donde la autoría está implícita.

4.1.2 Nivel Funcional: se refiere al propósito comunicativo del texto, este criterio lo clasifica en una 0 más funciones comunicativas, entre las que se encuentran: referencial, expresiva, apelativa, conativa, metalingüística, poética. ${ }^{6}$ Como el PEI es un discurso, cuyo propósito es

5 Respecto de este criterio hemos realizado algunas adaptaciones de los rasgos a considerar para describir el contexto situacional; éstos se construyeron inductivamente de acuerdo con las características del corpus utilizado (PEI) para permitir un análisis adaptado al contexto de los textos.

6 Estas son las funciones comunicativas más comunes; sin embargo, de acuerdo con los estudios, es difícil establecer una clasificación estática de las funciones de la comunicación, así como también identificar solo una de las funciones en los textos analizados. 
orientar todos los procesos educativos de la escuela, en el corpus predominan 3 tipos de funciones de la comunicación: referencial, apelativa y proyectiva.

Referencial: el corpus entrega un cúmulo de informaciones respecto del establecimiento educativo, su historia, características de la comunidad donde se inserta, propósitos y metas.

Apelativa: se orientan a la comunidad educativa para integrarlos en un proyecto común, persuadirlos de cómo llevar a cabo sus objetivos y producir una respuesta en la audiencia.

Proyectiva: PEI es un instrumento que orienta los procesos que ocurren en la escuela en función de un estado deseado, por ende, los textos se construyen proyectando una meta.

4.1.3 Nivel Textual: asociado a un plano netamente textual, a cómo se organiza el texto en su Microestructura y Macroestructura. Incluye los siguientes criterios:

- Estructura textual: refiere al patrón de organización del texto, el cual, en el caso de este corpus, presenta una estructura que vincula tanto elementos de orden descriptivo como normativo.

Descriptivos, por cuanto caracteriza a la escuela en relación con los actores que la constituyen, su historia, contexto, algunos de sus procesos, y planes a futuro.

Normativos, pues el PEI supone la determinación de un camino a seguir por los establecimientos a fin de llegar a ciertos objetivos deseados por la comunidad, para lo cual estructura una visión (estado deseado) misión (modo de llevarlo a cabo) y objetivos. Asimismo, define estados deseados respecto de los actores que componen la comunidad educativa, estableciendo "perfiles" y relevando aquellos valores que los distinguen como establecimiento educativo de otros.

- Tema: asociado a los temas que abarca el texto, es decir, evalúa si el texto es monotemático o pluritemático. Este corpus involucra diversos temas, pues su objetivo es definir los grandes procesos a desarrollar por la escuela, por lo tanto, el corpus es pluritemático.

- Multimodalidad: implica la inclusión o no en el texto de elementos de diversas modalidades (gráficos, lingüísticos). Este corpus solo incluye elementos lingüísticos, no utilizan otra clase de registros. Todo este análisis se puede ver resumido en la Tabla No.1 
Tabla No. 1

Análisis textual en base a enfoque multiniveles

\begin{tabular}{|c|c|c|c|c|c|c|c|c|}
\hline \multirow{2}{*}{\begin{tabular}{|c|} 
Tipo \\
textual
\end{tabular}} & \multicolumn{4}{|c|}{ Nivel Situacional } & Nivel Funcional & \multicolumn{3}{|c|}{ Nivel textual } \\
\hline & $\begin{array}{ll}\text { Ámbito } \\
\text { Producción }\end{array}$ & Audiencia & & Autor & $\begin{array}{l}\begin{array}{l}\text { Función } \\
\text { comunicativa }\end{array} \\
\end{array}$ & \begin{tabular}{|l|} 
Estructura \\
textual
\end{tabular} & Tema & $\begin{array}{l}\text { Multi- } \\
\text { modalidad }\end{array}$ \\
\hline $\begin{array}{l}\text { PEI } \\
\text { Católico }\end{array}$ & $\begin{array}{l}\text { Educacional y } \\
\text { religioso }\end{array}$ & $\begin{array}{l}\text { Externa, } \\
\text { experta, } \\
\text { lega }\end{array}$ & semi & $\begin{array}{l}\text { Explícito } \\
\text { colectivo }\end{array}$ & $\begin{array}{l}\text { yeferencial, } \\
\text { apelativa, } \\
\text { proyectiva }\end{array}$ & $\begin{array}{l}\text { Normativa } \\
\text { descriptiva }\end{array}$ & $\mid \begin{array}{l}\text { Pluri- } \\
\text { temático }\end{array}$ & Unimodal. \\
\hline PEI Laico & Educacional & $\begin{array}{l}\text { Externa, } \\
\text { experta, } \\
\text { lega }\end{array}$ & semi & $\begin{array}{l}\text { Implícito } \\
\text { explícito } \\
\text { colectivo }\end{array}$ & \begin{tabular}{|l} 
Referencial, \\
apelativa, \\
proyectiva
\end{tabular} & $\begin{array}{l}\text { Normativa } \\
\text { descriptiva }\end{array}$ & \begin{tabular}{|l} 
Pluri- \\
temático
\end{tabular} & Unimodal \\
\hline
\end{tabular}

\subsubsection{Macroestructura textual}

La Macroestructura corresponde al contenido general de un texto, se refiere al sentido del mismo como un todo (Huerta y García, 2007). Para determinarla, en primer lugar, se realizó un análisis del corpus en función de la frecuencia con que aparecen conceptos y palabras ${ }^{7} y$, posteriormente, se procedió a agruparlas a partir de los tópicos a los cuales hacen referencia y el sentido en que están incluidas en el texto.

Los tópicos generados a partir de las categorías y sus frecuencias se agruparon tal como aparece en el Gráfico No. 1.

Gráfico No. 1

Frecuencia de tópicos

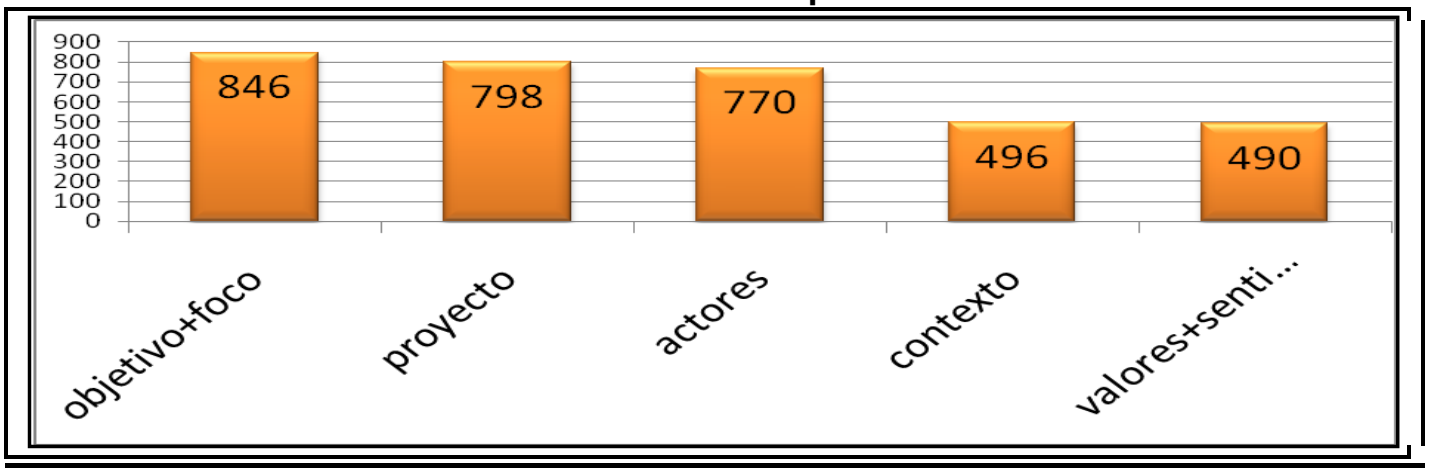

Fuente: Elaboración propia con base en conteo de palabras.

7 Se efectuó un conteo de conceptos o palabras, a través del software de análisis de datos cualitativos Atlas TI. 
De acuerdo con este análisis, el corpus examinado se organiza de acuerdo con el siguiente esquema de tópicos: el tema central es el Objetivo/foco, por cuanto el PEI es un instrumento que orienta todos los procesos que ocurren en la escuela en función de un estado deseado, de un futuro, por ende los textos se construyen proyectando una meta.

Para lo anterior, concurren actores, como partícipes y destinatarios de este objetivo, junto a ello se establece un camino lógico de actividades y procedimientos: el proyecto, situado a través de la especificación del contexto de acción de la escuela y orientado con base en sentidos y valores, ya sea laicos o religiosos.

Todo lo anterior se puede apreciar en el siguiente esquema:

\section{Esquema No. 1}

\section{Macroestructura textual}

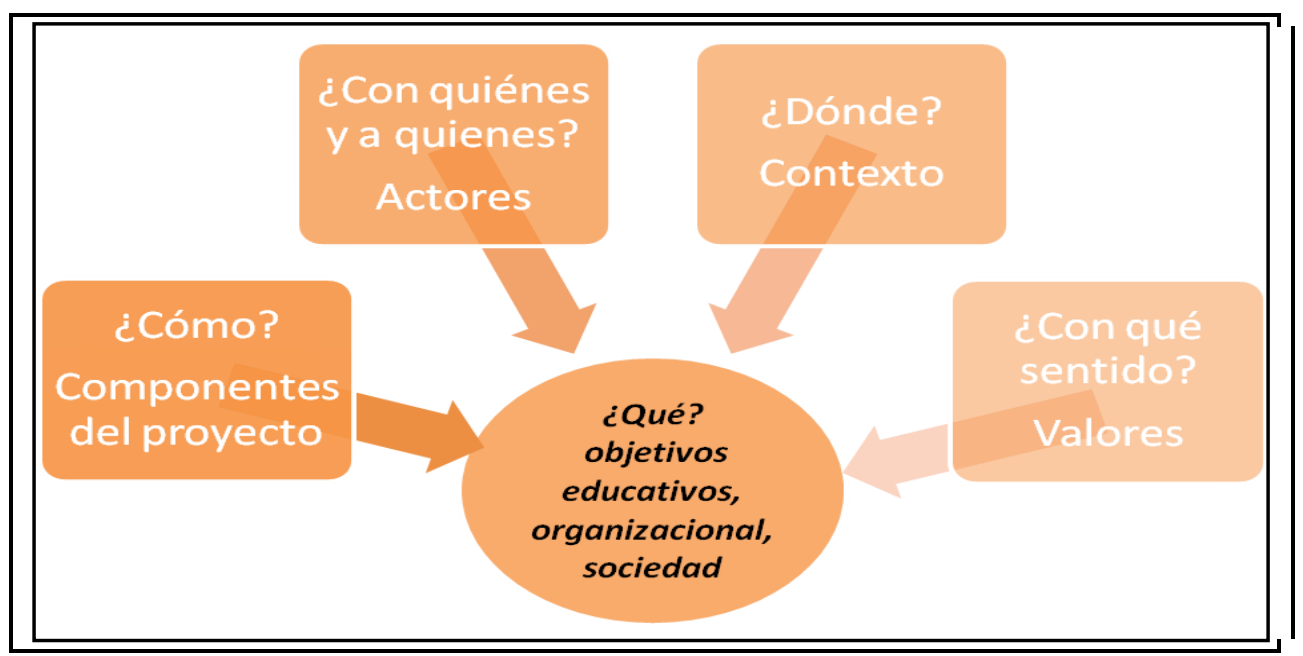

\subsection{Análisis Interpretativo ${ }^{8}$}

El objetivo central de este estudio fue el análisis de las concepciones de infancia que subyacen a los dispositivos discursivos de las escuelas, específicamente, a partir del PEI. Por ello, el corpus fue interrogado en cuanto a la presencia de ciertos tópicos relativos a nociones de infancia, para posteriormente desarrollar hipótesis interpretativas al respecto.

8 En el análisis que se presenta a continuación, las citas y los fragmentos que se incluyen corresponden a los proyectos educativos analizados; sin embargo, para procurar la privacidad de la información no se incluirán los nombres de los colegios correspondientes a cada cita. 


\subsubsection{Concepto de infancia}

Este tópico de análisis intentó relevar lo que se dice de la infancia en los documentos, los modos, las formas y las palabras con que se la nombra y se habla de ella. De acuerdo con lo anterior, es posible caracterizar el concepto de infancia de los proyectos educativos a partir de dos ideas fuerza: Ausencia y presencia contradictoria de la infancia.

\subsubsection{Desde la ausencia: marcos filosóficos o instrumentales}

El corpus analizado tiene como principal característica la ausencia y/o mención explícita de categorías referentes a la infancia como: niño, niña, infante, entre otras. El foco mayoritario de los PEI analizados lo constituyen categorías genéricas relativas a marcos filosóficos en los cuales se inspira el establecimiento, o bien, a criterios organizacionales pertenecientes a marcos conceptuales sobre gestión.

Así, respecto de aquellos PEI donde los idearios corresponden a marcos filosóficos los conceptos más utilizados son: persona, individuo, hombre, ser humano. Tal como aparece reflejado en las siguientes citas de los proyectos analizados

"La concepción filosófica que enmarca el quehacer educativo del colegio tiene su centro en la persona" (PEI).

"Concibe al ser humano como un individuo creado a imagen y semejanza de Dios, dotado de cuerpo y alma y llamado a una perfección natural y trascendente mediante el desarrollo del entendimiento y la voluntad" (PEI).

"Se requiere clarificar una visión de la persona que se pretende formar y definir la naturaleza última del ser humano (...) El concepto de modelo educativo se encontraría entonces en armonía con la noción de persona anteriormente establecida. Esto significa que los esfuerzos del Liceo se dirigirán a la totalidad de la persona, sin descuidar ningún aspecto" (PEI).

A partir de lo anterior, es posible inferir una suerte de asimilación/ invisibilización de la niñez, en el concepto de persona, pues no se habla directamente de la infancia, sino que se la concibe desde otros conceptos, en una suerte de espera: niñas y niños son considerados como "personas en proceso de formación".

En esta línea de la ausencia de la infancia en los PEI, aparece otro concepto genérico que 
se establece como objetivo de la escuela: lo organizacional, tema que aparece plasmado en las siguientes citas

"Finalidad del PEl: Tener una herramienta de gestión que guíe las acciones de la comunidad educativa, con principios, objetivos, metas y criterios comunes claros, que faciliten el quehacer institucional" (PEI).

"Evaluando sistemáticamente el desarrollo de los diferentes procesos de la escuela, proponiendo y ejecutando acciones que permitan mejorar la gestión de ésta" (PEI).

"El desarrollar una visión global de la organización escuela" (PEI).

Como se aprecia, hay una visión de la escuela con marcado énfasis instrumental, destacándose el carácter organizacional de la misma, en tanto se posicionan como prioridad los procesos de gestión y calidad del servicio educativo. Estas dinámicas aparecen nombradas en términos neutrales, invisibilizando la infancia al no aparecer ésta como sello distintivo, ni la presencia de los/as niños/as en el ideario de la escuela.

En este sentido, vemos que en la mayor parte de los PEI hay un claro énfasis por establecer fundamentaciones filosóficas, pedagógicas e incluso organizacionales. Sin embargo, ninguno de estos planteamientos se centra en niños y niñas, el colegio asume como concepto clave "la persona" o la "organización", a la cual le atribuye una serie de características y valores, es desde este concepto que el niño es observado, proyectado y evaluado, no como una entidad presente, diferenciada, sino en función de otro modelo. Lo anterior constituye un anacronismo, pues todo el proyecto se estructura con base en un concepto que no contiene a la niñez, o al menos no de manera explícita.

4.2.1.2 Desde la presencia: ¿personas incompletas, moratoria o niños en proceso de desarrollo?

Como ya se planteó, en los proyectos educativos mayoritariamente no existe mención explícita de la infancia, sino que las concepciones se encuentran directamente asociadas al concepto de persona, o bien, priorizan temas organizacionales como foco institucional.

Respecto de la asimilación de la infancia al concepto de persona, la imagen que entregan Ios PEl es la del/la niño/a como un ser incompleto, en tránsito hacia otras etapas, donde podrá ser plenamente una persona, ejemplo de lo anterior son las siguientes citas 
"El Colegio pretende que sus alumnos y alumnas tengan, al egresar, un perfil... en los niveles cognitivo, valórico y actitudinal" (PEI).

"El alumno que formamos debe llegar a ser una persona que reconozca en sí mismo, sus potencialidades" (PEI).

“La educación habrá de ayudar a cada alumna y alumno a desarrollar todo su potencial, a llegar a ser un sujeto, un ser humano completo" (PEI).

Esta idea de la niñez, marcada por lo que no es, expresa una visión de la infancia como una moratoria social, es decir, una etapa marcada por la espera y la preparación para el futuro.

La noción de futuro sitúa a la educación en una perspectiva proyectiva, en desmedro de su contribución al niño del presente. La educación adquiere un rol protagónico, puesto que es la encargada de formar a estos "futuros" hombres y mujeres, preparación qué, dependiendo del enfoque del colegio, es denominada a partir de categorías como: "formación", "conversión" e incluso "perfección".

En algunos casos pareciese existir un juicio de valor sobre la infancia, pues la adultez es situada como el estadio donde se alcanza la plenitud de virtudes y valores, en contraposición a esta etapa incompleta, donde hay que formarse para ser la persona que el colegio aspira

"Si el estudiante comprende y participa de la orientación que el colegio promueve, al término de su formación escolar, el/la joven será una persona solidaria, capaz de trabajar en equipo, resolver conflictos, adaptarse a los cambios, tolerar la frustración y ejercer un sano liderazgo" (PEI).

En esta línea, en el corpus aparece el concepto de conversión, el cual plantea un deber ser para la infancia, un imperativo de transformación delimitado a través del proceso educativo

"El niño y el joven están llamados a convertirse en individuos valiosos para sí mismos y para la sociedad. Sin embargo, esto no se realiza espontáneamente, sino que exige un esfuerzo consciente de formación que implica habituarse a la exigencia y al estudio serio" (PEI).

"Tiende a lograr la conversión del hombre en su dimensión personal y social" (PEI).

Una idea similar a la conversión, es el concepto de perfección, que también aparece en el corpus, donde se plantea explícitamente el ideal de perfeccionamiento moral, intelectual y 
físico de la infancia:

"Cada alumno/a, en cuanto persona, es respetado y valorado en su singularidad. Sobre esta base, se realizan los esfuerzos educativos, orientados a su perfeccionamiento moral, afectivo, intelectual y físico" (PEI).

"Esto demanda, tanto de sí mismo como de las demás personas, un respeto absoluto por su integridad moral, afectiva, intelectual y física y, a su vez, una búsqueda sincera de su perfeccionamiento." (PEI)

No obstante, algunos de los PEl analizados contienen concepciones de infancia caracterizadas por la presencia de niños y niñas, quienes aparecen mencionados explícitamente, siendo considerados el centro del accionar de la escuela, a través de la focalización de los procesos educativos en la mejora de sus aprendizajes

"Lograr que sus estudiantes se sientan felices, desarrollen habilidades y destrezas, que les proporcionen competencias y generen herramientas para crecer como persona integral" (PEI).

"Buscando nuevas metodologías que favorezcan el desarrollo integral de los educando Se habla explícitamente de los estudiantes y de la meta que ellos crezcan como personas" (PEI).

"Se deben buscar los medios para el desarrollo integral de los estudiantes" (PEI).

De estas declaraciones se pueden inferir concepciones de infancia donde el/la niño/a es visto/a como sujetos con múltiples capacidades. A diferencia de otros textos, aquí no se habla de formar a la persona, llegar a ser persona, sino que se utilizan los conceptos de: desarrollo, potencialidades, crecimiento, que no tienen la connotación de carencia o necesidad de completarse, sino que apuntan a la posibilidad de transformación, en tanto ser dinámico y con potencialidad de cambio.

Asimismo, en estos textos aparecen declaraciones cuyas concepciones de infancia denotan una articulación entre el/la niño/a presente con la preparación para el futuro. Asumiendo la importancia de que el proceso educativo se haga cargo de sus necesidades actuales, así como también de entregarle herramientas para futuros desafíos

"La escuela es una institución de educación prebásica y básica, dedicada a entregar conocimientos y valores a un nivel óptimo a niños del sector circundante, manteniéndolos 
en el sistema educativo, educando de tal manera que el alumno posea las herramientas necesarias y pertinentes para enfrentar tanto la convivencia social cotidiana como las exigencias de una educación de continuidad" (PEI).

"Educando se vaya desarrollando como persona humana integral. Por esto estimula y planifica el desarrollo físico, afectivo, artístico, intelectual, social y religioso. Esto lo desarrolla de una forma sistemática y progresiva, respetando en el proceso la libertad propia del educando, su situación socio-económica y su compromiso como ser trascendente" (PEI).

"Educar niños (as) y adolescentes que reconozcan sus capacidades, se responsabilicen de sus actos y desde allí desarrollen las herramientas necesarias para revertir la adversidad social y cultural" (PEI).

De lo anterior se desprende una visión de la infancia más cercana al enfoque de derechos, donde, por una parte, se los/as ve como seres con capacidades, responsabilidades, seres presentes, por otra parte, el texto habla de niños, niñas y adolescentes, construyendo la niñez como un grupo social con diferencias, en este caso de género y etáreas.

Así, emerge una mirada de la educación desde el hoy, planteándose para la infancia una experiencia educativa capaz de entregar herramientas para la convivencia cotidiana, en las múltiples dimensiones de la vida social.

\subsubsection{Infancia: ¿objeto de atención o sujeto de derecho?}

Este tópico refiere a todas las ideas expuestas en el corpus que: hablan y/u omiten el carácter de sujeto de derechos de niños y niñas; junto a aquellas respecto del ejercicio de derechos como autonomía, participación y protagonismo.

\subsubsection{Nociones de derechos}

Las concepciones de infancia que surgen del corpus, nuevamente están marcadas por la contradicción entre visiones que relevan el carácter de sujeto de niños y niñas con aquellas representaciones más tradicionales que los posicionan como objetos de atención, las cuales 
son las predominantes. Un ejemplo de esta paradoja se puede apreciar en la siguiente cita:

"El estudiante, en cuanto persona, es un sujeto irrepetible que está llamado a ser protagonista de su propia formación y de su historia. El colegio hará los esfuerzos necesarios para que el niño y la niña se perfeccionen moral, afectiva, intelectual y físicamente" (PEI).

En este fragmento se plantea que el/la estudiante constituye una persona irrepetible, se habla que él debe ser protagonista de su historia y formación, pero junto a ello se establece que el colegio tiene el rol de perfeccionarlo. Al respecto, si la escuela considera que niños y niñas deben perfeccionarse, y además predefine este proceso, cabe preguntarse acerca de las reales posibilidades de las que ellos sean protagonistas de su aprendizaje.

Este tipo de afirmaciones se asocian con la perspectiva tradicional de la infancia, y se agrupan en el corpus en torno a dos ideas mayoritarias: el modelamiento, control, y protagonismo de los adultos; así como también: el servicio, la protección y la ayuda.

Respecto de las primeras, surge con fuerza la idea del modelamiento a la infancia en base a un estilo predeterminado por la escuela

"En el colegio, los alumnos/as aprenden conocimientos específicos, pero, sobre todo, una manera de ser personal, coherente con el espíritu fundacional de esta institución. Este modo personal se caracteriza por la búsqueda de la excelencia, el amor al trabajo bien hecho, el autodominio y el respeto" (PEI).

"Habrán internalizado los valores de la verdad (...) Se comunicarán sin violencia y correctamente" (PEI).

Como se ve, prevalece una visión prescriptiva respecto de la infancia, reflejada en la idea de que aprendan "una forma de ser", donde el proceso educativo establece explícitamente un modelo de persona para el niño, y no se pronuncia respecto de las posibilidades y espacios que otorga la escuela para su autodeterminación. Otro planteamiento similar puede apreciarse en la siguiente cita

"El establecimiento utiliza como imagen institucional un joven que lee tranquilamente bajo un nogal. Con esto, se pretende simbolizar la robustez y serenidad del colegio, a cuya sombra se puede desarrollar el conocimiento y ejercicio de las virtudes, la reflexión seria y el cultivo del espíritu y el conocimiento" (PEI). 
En este caso, el texto concibe a niños y niñas como "depositarios" del proyecto institucional de la escuela, el cual es representado a través de este árbol, donde bajo su sombra se desarrolla el conocimiento y las virtudes. Esta imagen de un joven leyendo bajo un nogal, no hace mención explícita de niños y niñas, mientras que el protagonismo es puesto en la escuela que provee "sombra" a un niño que ocupa un papel secundario.

El segundo énfasis que aparece en el corpus, ligado a la concepción tradicional de la infancia, corresponde a la idea de protección para el niño, representado por conceptos como: acogida, servicio, ayuda, los cuales se pueden apreciar en las siguientes declaraciones

"La Escuela, tiene como misión servir a todos los niños de la localidad" (PEI).

"Disposición de escuchar y ayudar a sus alumnos" (PEI).

"El colegio acoge a los niños" (PEI).

Así vemos que desde la misión de la escuela se establece el trabajo con lo/as niño/as desde una noción de servicio y ayuda, no hay mención del carácter de derecho que tiene la educación, ni del rol garante que debe asumir la escuela. Esta ausencia es común en casi a todos los PEI analizados, ya sea a partir de la omisión del concepto de derechos, menciones secundarias, el condicionamiento de su ejercicio al cumplimiento de deberes, o incluso en contra de ellos.

Por ejemplo, en el siguiente fragmento existe una mención al derecho de la educación, pero a partir de una consideración bastante débil del mismo

"Competencias profesionales del docente: Respetar, a través de su quehacer pedagógico, el derecho de sus alumnos a aprender" (PEI).

Se aprecia que el rol del profesor se reduce a respetar el derecho a aprender, olvidando la responsabilidad de la educación y, por ende, de los docentes de ser garantes y responsables del ejercicio del derecho a una educación de calidad para todos los niños y niñas.

Por su parte, desde la idea del condicionamiento, surge en el corpus el tradicional binomio derechos/deberes a través del cual se establece como condición cumplir con los deberes para poder ejercer derechos, obviando el carácter adquirido de los mismos

"Capaz de poder cumplir con sus deberes en forma óptima, para exigir sin temor sus derechos" (PEI).

"En conformidad con lo anterior, una verdadera educación busca el justo equilibrio entre 
libertad y responsabilidad, lo que implica, por un lado, buscar el bien que verdaderamente perfecciona al individuo $y$, por otro, hacerse responsable por las decisiones personales adoptadas" (PEI).

Por último, aparecen afirmaciones que incluso van en contra de los derechos de niños y niñas, tal como la que se presenta a continuación

"Se espera respeto y adhesión por parte de los alumnos a este Proyecto Educativo. La persistencia en no respetar el espíritu de esta institución hace inviable la permanencia del alumno/a en cualquier establecimiento de la corporación".

Esta última idea nos revela una noción débil de la educación como derecho, por cuanto prima la selección, es decir, se educa sólo a aquellos niños y niñas que comparten el proyecto educativo del establecimiento, mientras que quienes no se adecúen a esto pierden la posibilidad de seguir en la escuela. Lo anterior se vuelve preocupante, sobretodo en contextos de vulnerabilidad, donde el derecho a la educación adquiere especial relevancia de modo de permitir mejores oportunidades de bienestar a niños y niñas.

La educación, como derecho, supone el acceso y la calidad de la misma para todos, independientemente de sus recursos económicos, opciones religiosas, culturales, etc. En estos textos la opción por educar a niños/as de contextos vulnerables tiene límites, pues opera un criterio de selectividad en el establecimiento, basado en los marcos valóricos de la institución.

\subsubsection{Ejercicio de derechos en términos de autonomía}

En el corpus existe una paradoja entre las ideas de autonomía y dependencia, tal como puede verse plasmado en el siguiente fragmento

"El establecimiento fomenta el aprendizaje autónomo de modo que los alumnos sean capaces de planificar y controlar su propio aprendizaje (...) La disciplina juega, a su vez, un papel crucial como herramienta educativa al enseñar el autodominio. A través de éste, los estudiantes adecuan su conducta a las exigencias del trabajo y la convivencia, aprendiendo a rectificar y a realizar un uso responsable de su libertad (...) Los patrones de rendimiento que demanda el colegio son exigentes por lo que se espera la disposición de los alumnos para adecuarse a un ritmo que, sin perjuicio de las capacidades naturales, 
siempre buscará la excelencia" (PEI).

Al respecto, en el texto se destaca el valor de la autonomía y el autodominio, pero, a la vez, se menciona la rectificación de la conducta de parte de niños y niñas. Esto se conecta con las "condiciones de exigencia del colegio" entidad que exige adhesión, define un patrón e impone un ritmo a niños y niñas.

En este plano cabe preguntarse acerca de las posibilidades que quedan para el estudiante de ejercer protagonismo y autonomía, pues se impone una imagen de la infancia caracterizada por la dependencia, a través de la disciplina, exigencia, y control.

Esta idea del control hacia la infancia, y delimitación de su participación aparece reflejada también en términos de su organización, expresión de ideas y opiniones.

"Mediante el Centro de Alumnos, los escolares organizan las actividades que le son propias con el apoyo de la Dirección. Esta participación sana y respetuosa no disminuye la autoridad del Equipo Directivo o de los profesores, ni tampoco altera la disciplina del centro escolar" (PEI).

"La participación cívica, que estimula la formación y presencia de un centro de alumnos, no debe confundirse con fines políticos particulares que sean contrarios al espíritu que anima esta institución" (PEI).

De estos fragmentos podemos inferir que la posibilidad de participación de niños y niñas aparece condicionada a la responsabilidad, el derecho a participar puede ejercerse si se adecua a la disciplina, y las ideas y organización de los estudiantes no pueden expresar proyectos políticos distintos a los del establecimiento. Estas declaraciones atentan contra una real autonomía de parte de los estudiantes, en términos de su libertad, creatividad y libre expresión.

Este énfasis en la disciplina se transforma en un aspecto común del corpus, y nuevamente se plantea como una idea contradictoria; por una parte, es definida como autorregulación, por parte de los/as estudiantes, pero, por otra, se conceptualiza como acatamiento de normas y rectificación, tal como aparece a continuación

"En virtud de lo anterior, la disciplina -entendida como el autodominio que ajusta la conducta propia a las exigencias del trabajo y la convivencia- cumple un papel fundamental al asegurar la armonía que cualquier proceso educativo necesita. En este sentido, es imprescindible que, por un lado, los estudiantes acaten las normas 
establecidas en el colegio y que, por otro, el centro educativo vea en la disciplina un instrumento educativo por el cual se hace reflexionar y rectificar a los estudiantes" (PEI).

Así, en el texto se configura una tensión entre la posibilidad de participar y el deber de obedecer, de acatar normas, pareciera pensarse que se tienen derechos siempre y cuando se asuman deberes y se tenga "responsabilidad".

No obstante, en el corpus es posible encontrar diversos planteamientos que destacan el valor de la autonomía tal como se aprecia a continuación

"Capaz de comprender y respetar su realidad personal y social (...) Capaz de pensar en forma creativa, reflexiva y auto-crítica, consciente de sus capacidades en conjunto únicas, que le permita continuar sus estudios o integrarse al medio laboral con seguridad y optimismo" (PEI).

"Apuntamos a la formación de una persona, única e irrepetible, responsable de su vida, gestora de su propio futuro, desarrollando armónicamente todas las potencialidades que posee como individuo" (PEI).

Este fragmento posiciona a niños y niñas con múltiples capacidades con razón y pensamiento, con consciencia de su realidad y diferencia. Asimismo, se releva su protagonismo, tanto en el proceso de aprendizaje como en su vida

"El alumno y la alumna, tienen la posibilidad de elegir entre actividades formativas diferentes, de acuerdo a las posibilidades del colegio y de su situación escolar (...) Se busca en común, con los alumnos y alumnas, la solución a los problemas, la mejor expresión de la verdad, las respuestas a las interrogantes fundamentales de la vida, el mejor modo de encarar los valores cristianos" (PEI).

A la vez, se identifican ideas que plantean de modo explícito la participación del/la niño/a en su propia formación, frente a lo cual el adulto es un mediador, o bien, asume un rol compartido y no prescriptivo.

\subsubsection{Diversidad}

Otra idea potente al interior del corpus refiere a la consideración de la diversidad, la cual 
es clave respecto de las concepciones de infancia que subyacen a los PEI, pues apunta a la conceptualización de ésta, ya sea como un grupo social diferenciado, o bien desde la homogeneidad.

Al respecto, en el corpus mayoritariamente se asume de manera explícita la diversidad, esta constituye la base, el contexto sobre el cual ocurre el aprendizaje

"Asumir la diversidad, donde todos los niños y niñas aprenden juntos bajo condiciones que les garantizan el desarrollo de las capacidades esenciales para su participación e integración social" (PEI).

"Aceptando por sobre todas las cosas, la diversidad e individualidad de las personas" (PEI).

Sin embargo, los textos difieren en el modo en que se estima la diversidad, el contenido que se le da, y las formas en que se incluye en el proceso de enseñanza-aprendizaje a través de estrategias y/o rol del adulto. Así, es posible identificar ideas donde ésta representa un valor, y se incluye una descripción de la misma, junto con planteamientos donde el concepto es mucho más limitado. De acuerdo con lo anterior, organizamos el análisis a partir de la tensión:

diversidad como valor, diversidad limitada.

\subsubsection{Diversidad como valor}

Respecto de aquellos textos donde hay una estimación positiva de la diversidad, esta es considerada como un valor, un elemento que aporta en el proceso educativo, frente a lo cual el adulto debe ser capaz de reconocer las diferencias de niños y niñas en términos de sus capacidades, talentos y contextos.

"La Escuela promoverá la no discriminación, para ello no seleccionará y en el futuro organizará el currículum de manera tal, que atienda la diversidad de sus alumnos y alumnas. Para ello, enseña considerando la realidad socio económico y cultural de los niños y sus distintos ritmos y estilos de aprendizaje. Atiende las diferencias individuales, procurando generar un clima de afecto y armonía" (PEI).

"Esta escuela atenderá a todo niño que quiera educarse, sin discriminación alguna" (PEI).

Vemos que se valora la diversidad, existiendo una opción manifiesta por trabajar con 
estudiantes sin distinciones y, de hecho, planteando iniciativas concretas para potenciar el acceso de diferentes niños y niñas a la escuela como es la: no selección.

En estos casos, se da contenido a la diversidad, a través de la incorporación en el proceso de enseñanza-aprendizaje del contexto en el que se encuentra la escuela, considerando la importancia de la realidad concreta de niños y niñas a la hora de lograr aprendizajes significativos. Así, la diversidad también es asociada a la situación socioeconómica de niños y niñas y sus familias, en términos de la riqueza que puede representar la convivencia de diversos sectores sociales, tal como se aprecia a continuación

"Un porcentaje no despreciable son familias de mejores recursos que han optado por vivir en este sector y sus hijos asisten a nuestro establecimiento, donde conviven distintas realidades sociales y económicas que permite una mayor diversidad e integración de toda la comunidad escolar".

Existe una consideración de las diferencias socioeconómicas presentes en el colegio (que ha hecho una opción preferencial por trabajar con personas en situación de vulnerabilidad) como una oportunidad de integración y de generar respeto a la diversidad, además, considerando la diversidad de familias como un valor y una responsabilidad.

Otro elemento en la estimación de la diversidad refiere al espacio y tareas que surgen para los docentes y directivos:

Respecto a sus Competencias Profesionales:

-Que manejan estrategias pedagógicas y recursos didácticos variados para facilitar el aprendizaje de todos los alumnos, siendo capaces de innovar y adaptar su labor según las necesidades, ritmos y estilos de aprendizajes, e intereses de cada uno (PEI).

-Capaces de transmitir altas expectativas sobre las posibilidades de aprendizaje y desarrollo de todos sus alumnos.

Respecto a su Compromiso:

-Comprometidas con el aprendizajes de todos sus alumnos.

Como se ve, se establece la necesidad de que el profesor debe manejar estrategias variadas, que se adapten a los alumnos: necesidades, estilos, intereses, ritmos. Asimismo, definen la transmisión de altas expectativas como parte del perfil del docente, junto con el 
compromiso y competencias para el aprendizaje de todos y el bienestar general (es decir, todos y en todo ámbito).

\subsubsection{Consideraciones más débiles de la diversidad respecto de la infancia}

Como ya se mencionó, pese a esta consideración positiva de la diversidad en la infancia, en el corpus también se identifican ideas más débiles de este concepto, donde si bien se menciona el respeto a la diversidad no se releva en términos de su contenido ni de estrategias para abordarla, e incluso, en algunos casos ésta se ve limitada por los valores y principios que inspiran el proyecto educativo.

Lo anterior se puede ver reflejado en los siguientes fragmentos

"Dentro de la persona humana, se distingue el hombre y la mujer. Ambos gozan de la misma dignidad y perfección, pero siendo distintos y complementarios. Esto supone respetar y fomentar la manera de ser mujer y la manera de ser hombre".

Aunque en términos genéricos, se considera la diversidad de género, esta se habla en términos de una manera de ser mujer y hombre, lo cual más que a apuntar a un reconocimiento diferenciado del género, refleja una mirada determinista del mismo en términos de roles.

Asimismo, aparecen consideraciones limitadas de la diversidad, también respecto de niños y niñas con necesidades educativas especiales

"En el caso de los estudiantes con dificultades de aprendizaje y que muestren una buena disposición, el establecimiento ofrece las instancias formales para que puedan mejorar y alcanzar los niveles mínimos aceptables por la institución".

El texto no nos habla de diversidad de niños-niñas, ni cómo eso podría ser un valor para el colegio. Cuando aparecen los niños con necesidades educativas especiales surgen, de parte del colegio, ciertas condiciones para regular su permanencia en el colegio: "muestran buena disposición".

Esta especie de "diversidad controlada", también se puede identificar en las siguientes citas:

"El Colegio está abierto a todos, sin distinción de ideología y credos, sin embargo, cuida que cada postulante sea respetuoso(a) de nuestra religión, nuestra enseñanza, nuestra 
forma de educación cristiana".

"(se) espera respeto y adhesión por parte de los alumnos a este Proyecto Educativo. La persistencia en no respetar el espíritu de esta institución hace inviable la permanencia del alumno/a en cualquier establecimiento de la corporación".

"Educar en la búsqueda del bien, la verdad, la justicia y la belleza a través de profesores que estén en constante perfeccionamiento moral e intelectual".

Al respecto, se aprecia una idea de diversidad donde la educación se establece como un espacio para acoger las diferentes opciones culturales, religiosas, etc. Sin embargo, este espíritu se contradice al condicionar la participación en el colegio a quienes no están de acuerdo con el PEI. La diversidad es aceptada siempre y cuando no atente con los valores que el establecimiento promueve, existiendo un marco institucional que determina el modelo de sujeto que se quiere formar, y de hecho mencionando la necesidad de perfeccionamiento moral de los profesores.

\subsubsection{Vulnerabilidad y/o pobreza en los PEl:}

Un último tópico que emerge del análisis de los PEI, corresponde a las temáticas de vulnerabilidad y pobreza en relación con la infancia. Esta dimensión en general se asume en la mayor parte del corpus a partir de la consideración de la realidad y características del contexto del cual provienen niños y niñas. Sin embargo, los énfasis, definiciones y proyectos de las escuelas al respecto son diferenciados. A partir de lo anterior surgen las siguientes ideas fuerza.

\subsubsection{Educar en vulnerabilidad implica considerar el contexto del cual provienen estudiantes y sus familias}

La mayoría de los PEI generan una caracterización detallada del contexto del cual provienen niños y niñas, apreciándose un especial énfasis por la inclusión del componente territorial y características socioeconómicas como inspirador del accionar de la escuela. En el corpus en general se habla explícitamente de pobreza y/o vulnerabilidad, es un tema presente en todo el documento, a partir de información territorial y de definiciones explícitas de focalización en pobreza. 
"Nuestros alumnos provienen de hogares de bajo nivel socioeconómico y educacional cuyos padres son en su mayoría trabajadores del sector agrícola, predominando los cultivos de frutas de exportación y actividades relacionadas con el rubro".

"La Escuela quiere llegar a ser una institución que entregue una formación que permita una educación integral y de calidad, equitativa y contextualizada, es decir, que considere las características del entorno rural y del nivel socio cultural y económico de sus alumnos".

De estas declaraciones se infiere que el proceso educativo para contribuir a la igualdad de oportunidades debe integrar las características, necesidades e intereses de los/as estudiantes. Asimismo, la consideración del contexto de vulnerabilidad releva el rol social de la educación y es reflejo de los valores orientadores de la escuela, donde educar en vulnerabilidad no es un asunto al azar, sino que es una opción de la escuela.

"El Centro Educacional está llamado a jugar un importante rol en el desarrollo de la zona rural, a través de la formación técnico profesional, ya sea en el colegio o mediante la creación de un Instituto Técnico Profesional u otros centros de estudios superiores, para hacer posible la inserción de sus alumnos en el mundo laboral y facilitar la continuidad a la educación superior".

"Soñar para aportar al desarrollo del entorno social".

Vemos un compromiso social fuerte en estos proyectos, donde la educación asume su contribución al proyecto de sociedad, y su influencia en las condiciones sociales de los sujetos.

En esta línea, la opción por educar en vulnerabilidad también puede ser, en algunos casos, para suplir un déficit de establecimientos educacionales cumpliendo un rol social, en la medida en que el derecho a la educación supone asegurar el acceso de todo/as

"A pesar del gran número de unidades educativas, existían áreas de la comuna con muy poca atención u oferta de educación para las niñas y niños de algunos sectores. Lo anterior era especialmente palpable en el sector sur-poniente de la comuna, y por tanto se traducía en una falta de cobertura para las necesidades educativas de un sector que experimentaba un crecimiento demográfico importante. (...) Producto de la situación de alta demanda y déficit de establecimiento en este sector".

"Se trasladó a la comuna de Huechuraba, debido a que en este sector (La Pincoya) había 
una necesidad inminente de apoyo cristiano, educacional y social”.

Pero, también, puede ser una opción valórica y congregacional, como es el caso de la mayor parte de los PEI católicos, donde la mirada de la pobreza y la opción de educar en estos contextos tiene directa relación con estos principios cristianos

“El Colegio tiene como destinatarios preferenciales a los niños, niñas y jóvenes de (...) y de las comunidades rurales que lo rodean con atención especial a aquellos cuyas carencias económicas son más profundas".

\subsubsection{Educar en vulnerabilidad implica trabajar con la comunidad y fortalecimiento de} la alianza familia escuela

Vinculado con la idea de una educación contextualizada, aparecen en el corpus las temáticas de familia y comunidad, en términos de su inclusión en el proceso educativo como agentes claves, sobretodo, en contextos de pobreza.

Al respecto, es común la mención a la comunidad, y como la escuela debe estar abierta a sus necesidades ofreciendo diversas alternativas.

"Este Liceo está abierto a la Comunidad, entregando actividades extra programáticas; deportivas, danza y baile para alumnos y apoderados del establecimiento y localidad".

"Considera como imperativo estratégico, abrir las escuelas a la comunidad y a su entorno, puesto que se deben buscar estrategias de acción que favorezcan la alianza entre el grupo familiar y la escuela. Además es necesario considerar que en una gestión educativa eficiente, se requiere generar mayores recursos a través de la creación de redes de apoyo".

Se aprecia una idea de escuela en tanto espacio abierto a la comunidad, un actor más dentro de un contexto donde se requiere superar la individualidad y trabajar en conjunto construyendo redes de apoyo. Así, la escuela se constituye en espacio de desarrollo, un recurso protector en para lo/as niño/as y sus familias.

Del mismo modo, en el corpus se habla de la familia pues el texto reconoce las características de ellas y las considera al momento de definir estrategias de trabajo. 
"Los padres de los alumnos tienen una comunicación intensa con el Colegio, gracias a una serie de proyectos conjuntos que favorecen la presencia, la formación, la capacitación y la participación de adultos".

"Desde el colegio siempre ha existido un gran interés y estimulación para que los padres y apoderados finalicen sus estudios".

Así, la incorporación de la familia a través de proyectos complementarios al proceso de enseñanza-aprendizaje de los/as estudiantes aparece como una estrategia educativa clave en contextos de vulnerabilidad.

4.2.4.3 Frente al imperativo de educar en vulnerabilidad existen diversas finalidades y concepciones de la pobreza

Al analizar el corpus se aprecian distintas conceptualizaciones de la situación de vulnerabilidad y/o pobreza existiendo tres énfasis principales: a) La Focalización en pobreza aparece como punto de partida, y el trabajo de la educación es propender a la integración social. b) Calidad y excelencia en la educación ¿pobreza como condición personal?, y c) Pobreza como castigo y necesidad de asistencia a los pobres.

\section{- La Focalización en pobreza aparece como punto de partida, y el trabajo de la educación} es propender a la integración social:

Aparece un concepto de pobreza amplio cuyo énfasis está en la integración social, asumiendo la diversidad de personas y un compromiso por una sociedad más justa.

"Su objetivo es promover la educación integral de los más pobres. La enseñanza, el compromiso y la dedicación a los niños y niñas de la comuna que viven en condiciones socioeconómicas desfavorecidas, procurando la integración y el respeto a las diferencias de acuerdo a sus realidades familiares".

\section{- Calidad y excelencia en la educación ipobreza como condición personal?}

En parte del corpus al hablar de pobreza se incluyen conceptos como el esfuerzo, rigor y la excelencia, los cuales enfatizan una mirada de este fenómeno como condición individual de 
las personas, sin pronunciarse respecto de las variables sociales y estructurales que originan las desigualdades.

"Desde su inicio, esta red de Colegios permitió que un número creciente de hombres y mujeres se educara, desarrollando el amor a la excelencia personal, al trabajo bien hecho y a la disciplina, pues sobre estas bases se edificaría la fortaleza de cada individuo y la de la floreciente nación (...). Fomentar la aspiración a la excelencia".

"El educador de nuestro Colegio pone énfasis en su labor en los alumnos menos capacitados afectiva, intelectual y socialmente, con el objeto de ayudarlos a superar sus debilidades".

De este modo, queda la sensación de que los pobres deben adquirir determinados valores para salir de su situación, frente a lo cual la educación actúa "perfeccionándolos", por ende, hay un primado de la educación como adaptación por sobre la educación como derecho. Otro planteamiento que refuerza este argumento de la primacía de la pobreza como condición individual aparece en el siguiente fragmento

"Promover la libertad de enseñanza y entregar educación de excelencia a niños y jóvenes de familias con dificultades económicas o situación social emergente".

Vemos que aparece como valor principal la libertad de enseñanza, por sobre la educación, la cual se entiende como una oferta (dice "entregar") de excelencia para niñosjóvenes y familias que tienen dificultades económicas; nuevamente se vincula la pobreza con condiciones individuales de los sujetos a través de los conceptos "dificultades", "situación social emergente".

\section{- Pobreza como castigo y necesidad de asistencia a los pobres:}

Otra de las líneas argumentativas respecto de la pobreza, que aparece en el corpus, corresponde a una mirada desde el servicio y la ayuda, posible de encontrar en varios de los PEl católicos.

"El colegio brinda el apoyo a las familias, amparándolas cada mes en reuniones".

"Nuestro colegio pondrá énfasis en acoger a niños y jóvenes del mundo rural, liberándolos de todo tipo de pobrezas". 
Se aprecian conceptos como acogida, servir, liberar, donde nuevamente la pobreza pareciera ser una condición individual de los sujetos, pero que en este caso son vistos como seres carenciados que requieren ayuda y amparo, negando con esto sus posibilidades de ser protagonistas en el desarrollo.

\section{Conclusiones}

A continuación, se expondrán las principales conclusiones de la investigación de acuerdo con los objetivos planteados y los niveles de análisis de discurso.

Respecto del primer objetivo perteneciente al nivel textual: Analizar las características textuales de los Proyectos Educativos Institucionales, a partir de criterios situacionales, funcionales y textuales, se obtuvo una clasificación del tipo textual al cual pertenecen los PEI, además de la definición de su macroestructura textual.

Respecto de los criterios situacionales, funcionales y textuales los principales elementos identificados son: en la dimensión situacional, el corpus analizado fue producido en el ámbito escolar, con excepción de aquellos pertenecientes a escuelas católicas que también son generados en las congregaciones religiosas.

De acuerdo con el estilo de los escritos, el corpus está dirigido a una audiencia experta, con conocimientos en el ámbito educativo, pues la mayor parte de los conceptos utilizados recogen aspectos disciplinares, o bien, utilizan conceptos técnicos.

La autoría de los documentos oscila entre aquellos que la declaran explícitamente, incluyendo descripciones de los procesos a través de los cuales se redactaron los PEI (mayoritariamente participativos) y otros donde permanece implícita.

En el ámbito funcional, relativo a las funciones comunicativas que expresa el del texto, predominan funciones referenciales, apelativas y proyectivas.

Por su parte, en relación a sus características textuales el corpus presenta una estructura eminentemente normativa, pluritemática y de formato unimodal.

Respecto de las temáticas que constituyen la macroestructura textual, el corpus se organiza de acuerdo al siguiente esquema: el tema central es el Objetivo/foco, por ende, los textos se construyen proyectando una meta. Para lo anterior, concurren actores, se establece 
un proyecto, los cuales se sitúan a través de la especificación del contexto y se orientan con base en sentidos y valores, ya sea laicos o religiosos.

A partir de esta caracterización, uno de los hallazgos que surgen es que la estructura textual de los PEI imposibilita que aparezca la noción de infancia, lo cual tiene como consecuencia la invisibilización del niño/a en el texto, pues al utilizar el formato de proyecto se privilegia la visión de futuro, los objetivos y metas a lograr, en desmedro del proceso educativo presente.

Esta estructura, además, tiene un fuerte carácter esquemático que le da un énfasis instrumental; más que una herramienta para soñar y orientar los procesos actuales y futuros de la escuela, se transforma en un instrumento de gestión.

En cuanto al segundo objetivo, de nivel interpretativo, correspondiente a Identificar los conceptos y características de las concepciones de infancia presentes en los Proyectos educativos Institucionales, constatamos la existencia de una concepción difusa respecto de la infancia, que vincula conceptos y valores asociados a la noción tradicional respecto de niños y niñas (dependencia, fragilidad, ausencia, entre otros), junto a aquellas asociadas al enfoque de derechos (autonomía, participación, protagonismo, etc.).

Lo anterior, también se expresa en la no categorización explícita de la niñez, se habla de la infancia al interior de categorías lejanas y neutras, que no recogen su especificidad. Lo cual es reflejo de la constante contradicción a la hora de pensar la infancia, porque se afirma que niños y niñas son el centro de la labor educativa, pero a la hora de plasmarlo en el discurso ellos son invisibilizados.

En este sentido, otra tensión que caracteriza las concepciones de infancia presente en los PEI tiene que ver con el tiempo y la construcción del sujeto niño como "individuo de paso". Se genera una paradoja entre el presente y el futuro que el PEI proyecta, donde el propio documento incluye esta "trampa" al ser un instrumento de planificación, destinado a orientar los procesos educativos en función de un objetivo futuro: el aprendizaje. Sin embargo, en esta acción proyectiva el discurso descuida al sujeto presente, al niño que hoy es parte de la escuela, cuyas necesidades son actuales.

Niños y Niñas no solo requieren formarse para "ser" en un futuro, para "convertirse en sujetos" y solo ahí integrarse a la sociedad. Ellos/as se forman también para estar hoy, para "siendo" aprender, y participar de la sociedad desde su especificidad actual, por ende, la meta 
de los PEI no puede reducirse al adulto educado o preparado para enfrentarse a la realidad, sino que debe, de manera necesaria, orientarse a los aprendizajes presentes.

En síntesis, vemos cómo las concepciones de infancia presentes en los PEI tienen como característica principal la contradicción (conviven conceptos de la niñez basados en visiones contrapuestas), la invisibilización de niños y niñas en sus discursos. (Se los menciona a través de categorías abstractas: persona, ser humano, etc.) Y la omisión del concepto de derechos de la infancia y carácter garante de la escuela.

Este hallazgo en los discursos no es trivial si consideramos los efectos de realidad que los discursos tienen sobre los sujetos, que deviene del carácter construido de lo social. A partir de los discursos generamos representaciones de la realidad, las cuales producen y re-producen modos de acción sobre la misma. En este sentido, los discursos no son construcciones lingüísticas neutras, ellos constituyen prácticas sociales y determinan fuertemente las actitudes y formas de relación entre los sujetos.

Por ello, si en el plano educativo operamos con base en discursos contradictorios acerca de la niñez, o bien, con base en categorías que destacan características negativas que limitan su autonomía, evidentemente, esto tiene un impacto en la configuración de los procesos de enseñanza y, en consecuencia, en las posibilidades de aprendizaje de los estudiantes, así como, también, influye en las propias representaciones que niños y niñas construyen de sí mismos.

\section{Referencias}

Alvarez, Gerardo. (2004). Textos y discursos: introducción a la lingüística del texto. Concepción, Chile: Unviersidad de Concepción.

Canales, Manuel. (1994). Las técnicas Cualitativas de Investigación Social. Santiago: Universidad de Chile.

Ceirano, Virginia. (2000). Las representaciones sociales de la pobreza. Cinta de moebio Revista de la Facultad de Filosofía Universidad de Chile. www.moebio.uchile.cl

Gaitán, Lourdes. (2006). El bienestar social de la infancia y los derechos de los niños. Política y Sociedad , 43 (1) 63-80

Gramajo, Aída; Parodi Giovanni. (2003). Los tipos textuales del corpus técnico profesional PUCV 2003: una aproximación multiniveles. Revista signos, 43 (54), 207-223. 
Grupo de Trabajo Niñez, equipo de Psicología y educación Universidad de Chile. (2006). Conceptualizaciones de la niñez desde la lectura de las políticas públicas en Infancia. Revista de Psicología Universidad de Chile , 15 (2), 49-56.

Huerta, María de Jesús; García, Roberto. (2007). Linguística del texto: superestructuras. Recuperado el 26 de octubre de 2010 http://sincronia.cucsh.udg.mx/

Narodowski, Mariano. (1994). La pedagogización de la Infancia. En Infancia y poder: la conformación de la pedagogía moderna (pp. 61-107). Buenos Aires: Editorial Aique.

Peña, Mónica. (2004). El niño como sujeto: el caso de la infancia y niñez en Chile en el siglo XX. Congreso Internacional de Educación, lenguaje y sociedad: tensiones educativas en América Latina. Santa Rosa- General Picó La Pampa Argentina: Universidad Nacional de la Pampa.

Propper, Flavia. (2001). Infancia y escuela: construcciones sociales en crisis. Recuperado 22 de Octubre 2010 www.nuestraldea.com

Quinteros, Graciela. (2003). Desarrollo humano e infancia. Revista Tramas (20), 61-79.

Rojas, Jorge. (2010). Historia de la Infancia en el Chile republicano 1810-2010. Santiago: 8 libros.

Rojas, Jorge. (2001). Los niños y su historia: un acercamiento conceptual y teórico desde la historiografía. Pensamiento crítico, revista electrónica de Historia, (1), 1-39

Rousseau, Jean-Jaques. (1966). Obras Selectas "El Emilio o de la Educación". Buenos Aires: El Ateneo.

Satriano, Cecilia. (2008). El lugar del niño y el concepto de infancia. Revista Extensión digital, (3), 1-7

Van Dijk, Teun. (2001). El Discurso como Interacción Social. Barcelona: Gedisa.

Villarroel, Sonia. (2002). Proyecto educativo institucional: Marco legal y estructura básica. santiago: Programa 900 escuelas, Ministerio de Educación .

Zepeda, Sandra. (2008). Leer desde el enfoque de derechos de niños y niñas los Reglamentos de convivencia escolar. Congreso Interregional de investigación en educación. Concepción Chile. 